\title{
Gastric Polyps in a Digestive Endoscopy Center in Dakar
}

\author{
Marie Louise Bassene1, Salamata Diallo1, Mame Aïsse Thioubou1, Aïchetou Diallo1, \\ Mamadou Ngone Gueye ${ }^{2}$, Mamadou Lamine Diouf ${ }^{1}$
}

${ }^{1}$ The Department of Hepato-Gastroenterology, Aristide Le Dantec Hospital, Dakar, Senegal

${ }^{2}$ The Department of Hepato-Gastroenterology, General Hospital of Grand Yoff, Dakar, Senegal

Email: marielouisebassen@yahoo.fr

How to cite this paper: Bassene, M.L., Diallo, S., Thioubou, M.A., Diallo, A., Gueye, M.N. and Diouf, M.L. (2017) Gastric Polyps in a Digestive Endoscopy Center in Dakar. Open Journal of Gastroenterolo$g y, 7,279-286$.

https://doi.org/10.4236/ojgas.2017.710029

Received: September 21, 2017

Accepted: October 28, 2017

Published: October 31, 2017

Copyright ( 92017 by authors and Scientific Research Publishing Inc. This work is licensed under the Creative Commons Attribution International License (CC BY 4.0).

http://creativecommons.org/licenses/by/4.0/

\begin{abstract}
Introduction: The gastric polyp is a tumor protruding into the gastric lumen. It is asymptomatic most often with a risk of malignant degeneration closely related to its histological nature. These data are very rare in Africa. Objectives: Reporting the frequency and endoscopic and histological characteristics of gastric polyps in the digestive endoscopy center of Aristide Le Dantec hospital in Dakar. Patients and methods: This was a retrospective study carried out in the digestive endoscopy center of Aristide Le Dantec Hospital in Dakar from January 2012 to December 2016. We have included all patients with one or more gastric polyps coupled with histological findings available. Results: There were 60 patients with gastric polyps, hence a prevalence of $0.8 \%$. We included 37 patients. Their mean age was 46 years [ 21 years - 75 years]. The sex-ratio was 0.48 . Epigastralgia was the most frequent endoscopic indication (51.3\%). The polyp was unique in 26 patients $(70.3 \%)$ with an average size of $6.87 \mathrm{~mm}$ [2 - $15 \mathrm{~mm}$ ]. Polyps were sessile in 31 cases $(83.8 \%)$ and pediculate in 6 cases $(16.2 \%)$. They were most often in the antrum (51.4\%). Antral erosions $(13.5 \%)$ and fundic atrophy (13.5\%) were the main associated endoscopic lesions. These were hyperplastic polyps in $27 \%$ of cases and adenoma in $16.2 \%$ of cases. Chronic atrophic gastritis (10.8\%) and intestinal metaplasia $(10.8 \%)$ were the main histological lesions associated with polyps. Helicobacter pylori $(H p)$ were present in 17 patients $(45.9 \%)$. Conclusion: The prevalence of gastric polyps is $0.8 \%$ in the endoscopy center of Aristide Le Dantec hospital. They are usually hyperplastic or adenomatous.
\end{abstract}

\section{Keywords}

Gastric Polyps, Gastric Hyperplastic Polyps, Gastric Adenoma, Sub-Saharan Africa 


\section{Introduction}

The gastric polyp is a tumor protruding into the gastric lumen independently of its histological nature.

It is mostly asymptomatic, of fortuitous discovery during an upper digestive endoscopy.

The risk of malignant degeneration of gastric polyps is closely related to their histological nature. It is more important for adenomas.

In Western countries, the frequency of gastric polyps varies between $2 \%$ and 6\% [1] [2]. In sub-Saharan Africa and Senegal in particular, the prevalence of gastric polyps is poorly understood due to the scarcity of published data.

The treatment of these polyps varies according to their symptomatic character or not but also depending on their histological nature.

We report the frequency and endoscopic and histological characteristics of gastric polyps in the digestive endoscopy center of Aristide Le Dantec hospital in Dakar.

\section{Patients and Methods}

We carried out a retrospective study in the endoscopy center of Aristide Le Dantec hospital in Dakar during the period from 1 January 2012 to 31 December 2016. Our study population consisted of all patients referred to the Center for an upper digestive endoscopy, regardless of indication. We included all patients who presented one or more gastric polyps.

Biopsies or excisional biopsies with a biopsy forceps were performed in all patients according to the size and number of polyps. Biopsies were also done on the rest of the gastric mucosa in search of associated lesions.

Patients whose histological history was not available were excluded from the study.

In the upper gastrointestinal endoscopy registries, we collected and analyzed data on age, sex, indications for the examination, and endoscopic and histological findings.

\section{Results}

\subsection{Epidemiologic Aspects}

During the study period, 7152 upper digestive endoscopies were performed. The examination found one or more polyps in 60 patients, hence a prevalence of $0.8 \%$.

Twenty-three patients were excluded from the study due to the unavailability of histological reports.

Thus, we included 37 patients. The mean age was 46 years $[21$ years - 75 years]. There were 25 women and 12 men, a sex ratio of 0.48 .

\subsection{Clinical Aspects}

Epigastralgia was the most frequent indication of upper digestive endoscopy 
(51.3\%). Five patients (13.5\%) were referred to the center for polypectomy (see Table 1).

\subsection{Endoscopic Aspects}

The endoscopic examination found a single polyp in 26 patients (70.3\%), 2 to 10 polyps in 6 patients (16.2\%) and more than 10 polyps in 5 patients (13.5\%).

The average size of the polyps was $6.87 \mathrm{~mm}[2-15 \mathrm{~mm}$ ]. It was not specified in seven cases (16.2\%). It was less than $10 \mathrm{~mm}$ in $56.7 \%$ of the cases (Figure 1 ).

Polyps were sessile in 31 cases (83.8\%) and pediculate in 6 cases (16.2\%). They are located in the antrum in 19 patients (51.4\%), in the fundus in 16 patients (43.2\%), and in the antrum and the fundus in 2 patients (5.4\%).

They were associated with other lesions in 22 patients (Figure 2). The most

Table 1. Frequency of indications for upper gastrointestinal endoscopy.

\begin{tabular}{ccc}
\hline Indications & Numbers & Percentage \\
\hline Epigastralgia & 19 & 51.3 \\
Polypectomy & 5 & 13.5 \\
Control of polyp & 1 & 2.7 \\
Control of hemorrhagic GU & 1 & 2.7 \\
PH diagnosis & 3 & 8.1 \\
PVS dilation & 2 & 5.4 \\
Dysphagia & 3 & 8.1 \\
Hiccoughs & 1 & 2.7 \\
LEV & 1 & 2.7 \\
Biermer's disease & 1 & 2.7
\end{tabular}

Legend: GU: Gastric ulcer; PH: Portal hypertension; PVS: Plummer Vinson Syndrome; LEV: Ligature of esophageal varices.

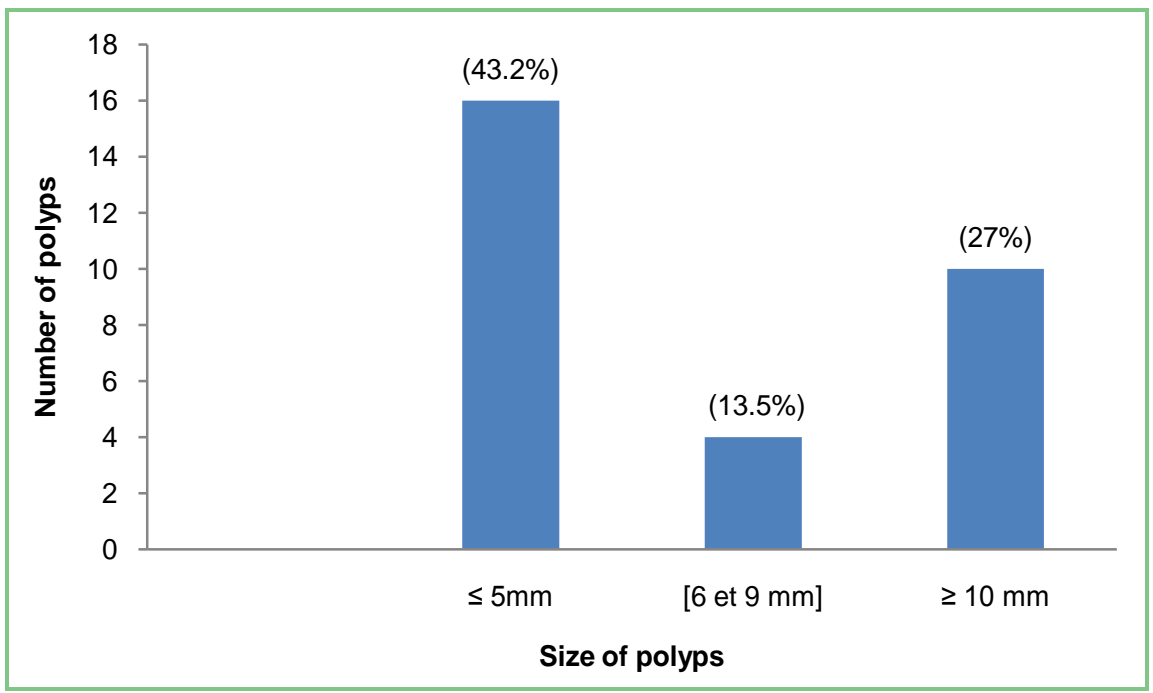

Figure 1. Repartition of polyps by size. 
frequent lesions were the antral erosions in 5 cases (13.5\%) and the fundic atrophy in 5 cases (13.5\%).

\subsection{Histologic Aspects}

Histological examination was in favor of chronic gastritis known as chronic pseudo-polypoid gastritis in $40.5 \%$ of cases, hyperplastic polyps in $27 \%$ of cases, adenoma in $16.2 \%$ of cases (Figure 3 ).

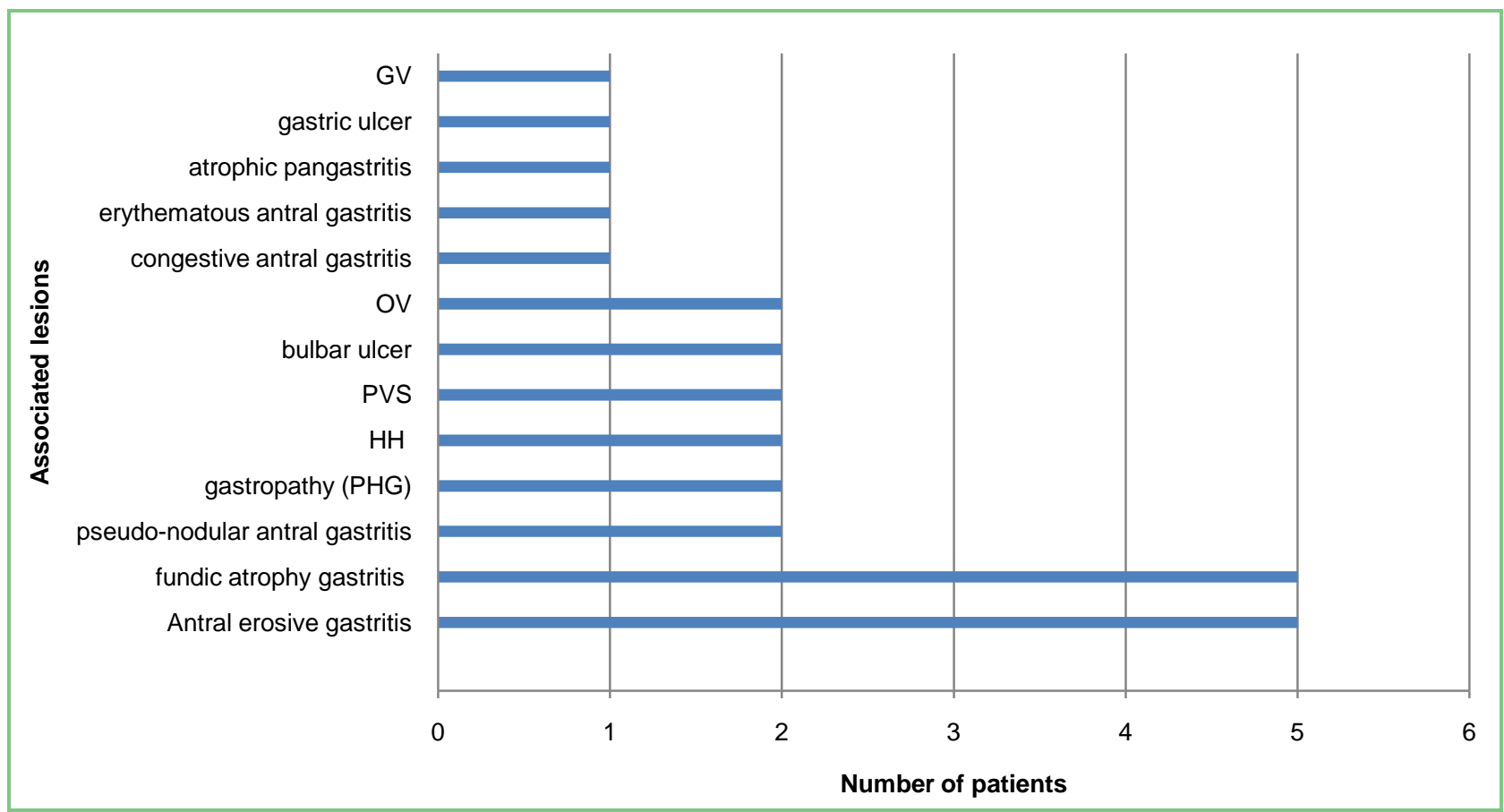

Figure 2. Repartition of the different associated endoscopic lesions. Legend: PHG: Portal hypertensive gastropathy; HH: Hiatal hernia; PVS: Plummer-Vinson Syndrome; GV: gastric varices; OV: esophageal varices.

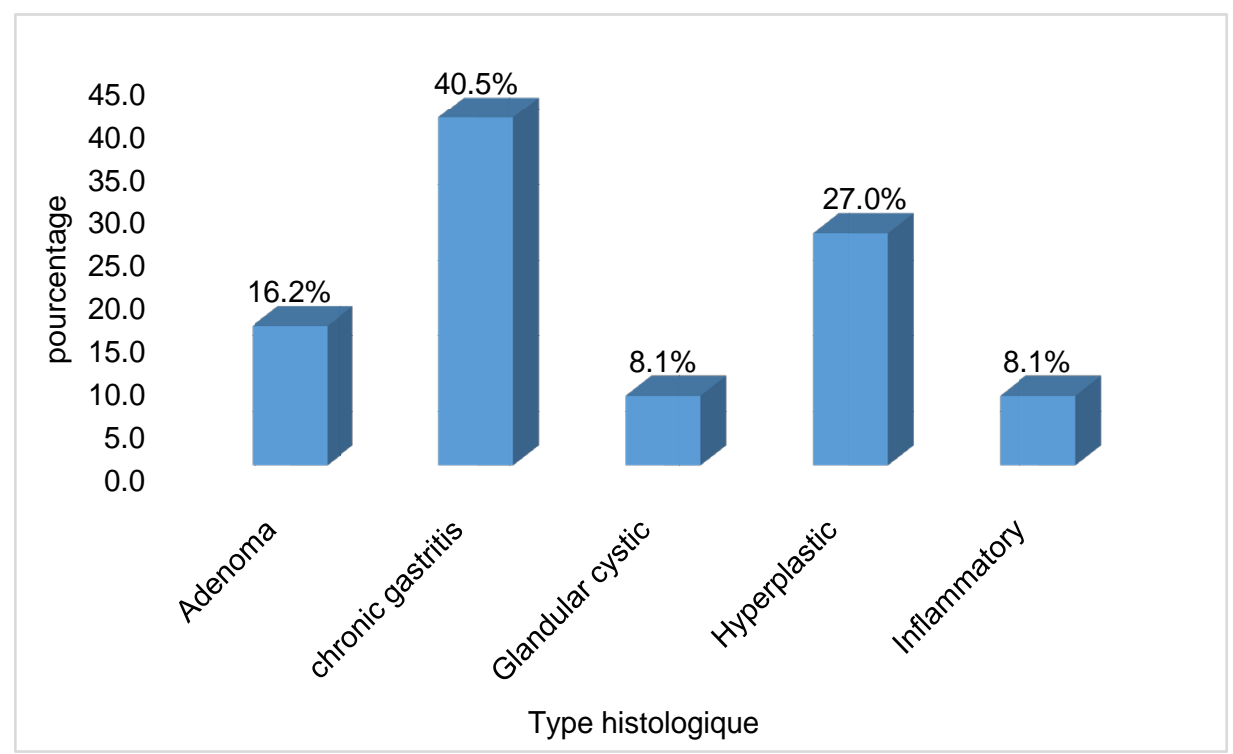

Figure 3. Repartition of polyps by histologic type. 
Chronic atrophic gastritis $(10.8 \%)$ and intestinal metaplasia $(10.8 \%)$ were the main associated histological lesions (Table 2).

Helicobacter pylori $(H p)$ was present in 17 patients (45.9\%).

\section{Discussion}

The prevalence of gastric polyps in the digestive endoscopy center of Aristide Le Dantec University Hospital in Dakar was $0.8 \%$. A study carried out in the same center in 1994 over a period of 4 years found a prevalence of $0.4 \%$ [3].

In Africa, the prevalence varies between $0.93 \%$ and $3 \%$ [4] [5] [6]. It is $2.4 \%$ in Portugal [7], 3.75\% and 7.72\% in two American studies [2] [8] and 0.58\% in Brazil [9]. In China, Endian et al. estimated it at 3.1\% [10].

Thus, there is great variability in the prevalence of gastric polyps in the world; this prevalence appears to be higher in the northern countries. This disparity could be related to the specificities of each study population, the study methodology and the level of performance of the technical platform.

The mean age of patients was 46 years. The average age of discovery of gastric polyps is variable in the literature. Thus, it was 54.15 years in Morocco [6] and 54.7 years in China [11], whereas in Portugal and Spain it was 60.4 years and 64.9 years respectively [7] [12]. However, it is assumed that the frequency of polyps increases with age, especially from age 40 [2] [9] [11] [13] [14] [15].

Epigastralgia was the main indication of upper digestive endoscopy (51.3\%). Their frequency was $33.8 \%$ in Tunisia [6]. In Portugal and China, dyspepsia was the predominant indication, with rates of $41.5 \%$ and $37.3 \%$, respectively [7] [10].

Gastric polyps are predominantly asymptomatic. They are most often discovered accidentally during an upper digestive endoscopy. In our study, polyps were unique in the majority of patients (70.3\%) and averaged $6.87 \mathrm{~mm}$. Their size was less than $10 \mathrm{~mm}$ in $56.7 \%$ of the cases.

Polyps occur most often in a sporadic context as shown by several studies [6] [8] [9] [16]. The greatest frequency of small polyps is also reported in the literature [7] [9] [12] [17].

Table 2. Associated histologic lesions by polyp types.

\begin{tabular}{ll}
\hline Types of polyps & Associated histologic lesions \\
\hline Adenomatous Polyps & $\begin{array}{l}1 \text { atrophic gastritis }(16.7 \%) \\
1 \mathrm{Hp} \text { infection }(16.7 \%)\end{array}$ \\
Glandular Cystic Polyps & No associated histological lesions \\
& 4 atrophic gastritis (40\%) \\
Hyperplastic polyps & 3 Hp infections $(30 \%)$ \\
& 1 intestinal metaplasia $(10 \%)$ \\
Inflammatory polyps & 1 low grade dysplasia $(33.3 \%)$ \\
& 2 low-grade dysplasia $(13.3 \%)$ \\
Chronic pseudo-polypoid gastritis & 6 intestinal metaplasia $(40 \%)$ \\
& 13 Hp infections $(86.7 \%)$
\end{tabular}


Hyperplastic polyps were the most common histological type (27\%). They were associated with alterations in the gastric mucosa with atrophic gastritis in $40 \%$ of cases and intestinal metaplasia in $10 \%$ of cases. There was an $\mathrm{Hp}$ infection in $30 \%$ of cases.

Indeed, it is admitted that hyperplastic polyps develop most commonly within an inflammatory gastric mucosa infected with $H p$ [18] [19] [20].

As atrophy of the gastric mucosa is likely to lead to negativity in the histological investigation of $H p$, a former infection cannot be ruled out.

These alterations of the gastric mucosa, mostly secondary to infection with $H p$ are risk factors for gastric adenocarcinoma and an indication for the eradication of $H p$ [21].

Adenomatous polyps were present in 6 patients (16.2\%). They were associated with atrophic antral gastritis in 1 patient and an $H p$ in 1 patient as well.

Adenomas are precancerous lesions that must be resected. Their association with chronic gastritis is described in the literature [6] [16] [22].

The role of $H p$ infection in the onset of gastric adenomas has been studied by several authors who have shown an increase in $H p$ infection in patients with gastric adenomas and a disappearance or decrease in the size of adenomas after eradication of $H p$ [23] [24].

In our study, a single patient with an adenoma was a carrier of $H p$, which did not allow it to be incriminated in the genesis of gastric adenomas.

\section{Conclusions}

Gastric polyps are heterogeneous lesions. Depending on their nature, they may become potentially malignant. Their prevalence was $0.8 \%$ in the digestive endoscopy center of Aristide le Dantec hospital in Dakar. Hyperplastic and adenomatous polyps were the most frequent histological types. They were sometimes associated with chronic atrophic gastritis and/or $H p$ infection that are recognized as pre-neoplastic states.

Despite the relatively low incidence of gastric cancer in sub-Saharan Africa, mortality remains high due to delayed diagnosis. Prevention is based on the excision of polyps, especially adenomas, which constitute pre-cancerous lesions and regular endoscopic follow up.

The influence of $H p$ infection on the natural history of certain polyps or the associated mucosal lesions it induces requires its investigation and eventual eradication in all cases to reduce the risk of cancer or recurrence after excision.

\section{Conflict of Interest}

none.

\section{References}

[1] Archimandritis, A., Spiliadis, C., Tzivras, M. et al. (1996) Gastric Epithelial Polyps: A Retrospective Endoscopic Study of 12,974 Symptomatic Patients. The Italian 
Journal of Gastroenterology, 28, 387-390.

[2] Carmack, S.W., Genta, R.M., Schuler, C.M. and Saboorian, M.H. (2009) The Current Spectrum of Gastric Polyps: A 1-Year National Study of over 120,000 Patients. The American Journal of Gastroenterology, 104, 1524-1532. https://doi.org/10.1038/ajg.2009.139

[3] Ouattara, A. (1994) Bilan de l'endoscopie digestive haute : à propos de 2434 examens effectués au CHU de l'hôpital Aristide Le Dantec en 4 ans. Approche préliminaire de l'épidémiologie des maladies oeso-gastroduedénales. Thèse de Doctorat, Faculté de médecine, de Pharmacie et d'odonto-stomatologie de l'université Cheikh Anta Diop de Dakar, Sénégal.

[4] Sidibé, A. (2009) Etude épidémiologique et histologique des pathologies gastriques diagnostiquées à l'INRSP de 2005 à 2006. Thèse de Doctorat, Faculté de médecine, de Pharmacie et d'odonto-stomatologie du Bamako, Mali.

[5] Ibara, J.R., Moukassa, B. and Itoua-Ngaporo, A. (1993) La pathologie digestive haute au Congo à propos de 2393 endoscopies réalisées au C.H.U de Brazzaville. Médecine d'Afrique Noire, 40, 97-100.

[6] Goubraim, R. (2012) Polypes gastriques sporadiques, quelle prise en charge? Expérience d'un service marocain. Endoscopy, 44, A006353fr. https://doi.org/10.1055/s-0032-1305695

[7] Brandao, C., Fernandes, N. and Mesquita, N. (2006) Gastric Polyps-A Review of 321 Cases. Gastroenterology, 13, 126-131.

[8] Sonnenberg, A. and Genta, R.M. (2015) Prevalence of Benign Gastric Polyps in a Large Pathology Database. Digestive and Liver Disease, 47, 164-169. https://doi.org/10.1016/j.dld.2014.10.004

[9] Morais, D.J., Yamanaka, A., Zeitune J.M. and Andreollo, N.A. (2007) Gastric Polyps: A Retrospective Analysis of 26,000 Digestive Endoscopies. Arquivos de Gastroenterologia, 44, 14-17. https://doi.org/10.1590/S0004-28032007000100004

[10] Zheng, E., Ni, S., Yu, Y., Wang, Y., Weng, X. and Zheng, L. (2015) Impact of Gender and Age on the Occurrence of Gastric Polyps: Data Analysis of 69575 Southeastern Chinese Patients. Turkish Journal of Gastroenterology, 26, 474-479. https://doi.org/10.5152/tjg.2015.0099

[11] Fan, N., Yang, J. and Sun, G. (2015) Changes in the Spectrum of Gastric Polyps in the Chinese Population. World Journal of Gastroenterology, 7, 9758-9764. https://doi.org/10.3748/wjg.v21.i33.9758

[12] García-Alonso, F.J., Martín-Mateos, R.M., González Martín, J.A., Foruny, J.R., Vázquez-Sequeiros, E. and Boixeda de Miquel, D. (2011) Gastric Polyps: Analysis of Endoscopic and Histological Features in Our Center. Revista Espanola De Enfermedades Digestivas, 103, 416-420. https://doi.org/10.4321/S1130-01082011000800005

[13] Cao, H., Wang, B. and Zhang, Z. (2012) Distribution Trends of Gastric Polyps: An Endoscopy Database Analysis of 24121 Northern Chinese Patients. Journal of Gastroenterology and Hepatology, 27, 1175-1180. https://doi.org/10.1111/j.1440-1746.2012.07116.x

[14] Gencosmanoglu, R., Sen-Oran, E. and Kurtkaya-Yapicier, O. (2003) Gastric Polypoid Lesions: Analysis of 150 Endoscopic Polypectomy Specimens from 91 Patients. World Journal of Gastroenterology, 9, 2236-2239. https://doi.org/10.3748/wjg.v9.i10.2236

[15] Sivelli, R., Del Rio, P., Bonati, L. and Sianesi, M. (2002) Gastric Polyps: A Clinical Contribution. Chirurgia Italiana, 54, 37-40. 
[16] Salihoun, M., Stock, N., Rioux, N., D’Halluin, P.N., Manfredi, S., Bretagne, J.F., et al. (2009) Polypes Gastriques Sporadiques: Aspect Endoscopique, Histologique et Pronostic. À propos de 75 cas. Acta Endoscopica, 39, 236-243. https://doi.org/10.1007/s10190-009-0085-0

[17] Liu, Q. (2012) Gastric Polyps: Are We Following Guidelines? Gut, 61, A369. https://doi.org/10.1136/gutjnl-2012-302514d.179

[18] Elhanafi, S., Saadi, M. and Lou, W. (2015) Gastric Polyps: Association with Helicobacter Pylori Status and the Pathology of the Surrounding Mucosa, across Sectional Study. World Journal of Gastrointestinal Endoscopy, 7, 995-1002.

[19] Carmack, S.W., Genta, R.M., Graham, D.Y. and Lauwers, G.Y. (2009) Management of Gastric Polyps: A Pathology-Based Guide for Gastroenterologists. Nature Reviews Gastroenterology \& Hepatology, 6, 331-341.

https://doi.org/10.1038/nrgastro.2009.70

[20] Feng, J., Zi-Wei, W. and Jian-Wen, N. (2006) Effect of Drug Treatment on Hyperplastic Gastric Polyps Infected with Helicobacter Pylori: A Randomized, Controlled Trial. World Journal of Gastroenterology, 21, 1770-1773.

[21] Uemura, N., Okamoto, S. and Yamamoto, S. (2001) Helicobacter Pylori Infection and the Development of Gastric Cancer. The New England Journal of Medicine, 345, 784-789. https://doi.org/10.1056/NEJMoa001999

[22] Abraham, S.C., Montgomery, E.A., Singh, V.K., Yardely, J.H. and Wu, T.T. (2002) Gastric Adenomas: Intestinal-Type and Gastric-Type Adenomas Differ in the Risk of Adenocarcinoma and Presence of Background Mucosal Pathology. The American Journal of Surgical Pathology, 26, 1276-1285. https://doi.org/10.1097/00000478-200210000-00004

[23] Gotoda, T., Saito, D. and Kondo, H. (1999) Endoscopic and Histologic Reversibility of Gastric Adenoma after Eradication of Helicobacter Pylori. Journal of Gastroenterology, 34, 91-96.

[24] Komoto, K., Hamura, K. and Kamada, T. (1998) Helicobacter Pylori Infection and Gastric Neoplasia: Correlations with Histologic Gastritis and Tumor Histology. The American Journal of Gastroenterology, 93, 1271-1276.

https://doi.org/10.1111/j.1572-0241.1998.00408.x 